Etnográfica

Revista do Centro em Rede de Investigação em

Antropologia

vol. 16 (1) | 2012

Vol. $16(1)$

\title{
Negociações identitárias dos luso-descendentes no Canadá através do futebol português e do hóquei no gelo canadiano
}

Identity negotiations of luso-descendants in Canada through Portuguese football and Canadian ice hockey

\section{João Sardinha}

\section{(2) OpenEdition}

\section{Journals}

\section{Edição electrónica}

URL: https://journals.openedition.org/etnografica/1424

DOI: 10.4000/etnografica.1424

ISSN: 2182-2891

\section{Editora}

Centro em Rede de Investigação em Antropologia

\section{Edição impressa}

Data de publição: 1 fevereiro 2012

Paginação: 143-162

ISSN: 0873-6561

\section{Refêrencia eletrónica}

João Sardinha, «Negociações identitárias dos luso-descendentes no Canadá através do futebol português e do hóquei no gelo canadiano», Etnográfica [Online], vol. 16 (1) | 2012, posto online no dia 06 março 2012, consultado o 12 fevereiro 2022. URL: http://journals.openedition.org/etnografica/ 1424 ; DOI: https://doi.org/10.4000/etnografica.1424

\section{(c) (†) 8}

Etnográfica is licensed under a Creative Commons Attribution-NonCommercial 4.0 International License. 


\section{Negociações identitárias dos luso-descendentes no Canadá através do futebol português e do hóquei no gelo canadiano}

\section{João Sardinha}

O presente artigo analisa os modos como os descendentes de imigrantes portugueses no Canadá, tendo crescido neste país mas sob a influência das suas raízes portuguesas, concebem, formulam e negociam as suas identidades por meio dos desportos favoritos dos dois países a que estão ligados - o futebol, no caso de Portugal; o hóquei no gelo, no caso do Canadá. As conclusões apresentadas baseiam-se em dados empíricos recolhidos mediante entrevistas semiestruturadas e conversas informais com luso-descendentes durante um período de trabalho de campo que decorreu entre 2 de outubro e 5 de novembro de 2009 nas cidades canadianas de Toronto, Otava-Gatineau e Montreal.

PALAVRAS-CHAVE: futebol, hóquei no gelo, descendentes de emigrantes portugueses, Canadá, identidade.

Identity negotiations of luso-descendants in Canada through Portuguese football and Canadian ice hockey - This paper examines the ways descendants of Portuguese immigrants in Canada, raised under the shroud of their Portugal ancestry, contemplate, formulate and negotiate their identities via the two primary sporting pastimes of the two countries: soccer, in the case of Portugal; ice hockey, in the case of Canada. The findings presented in this article are based on empirical data collected through semis-structured interviews and casual conversations with Portuguese-Canadian descendants during a fieldwork period that took place from October $2^{\text {nd }}$ to November $5^{\text {th }}$ of 2009 in the Canadian cities of Toronto, Ottawa-Gatineau and Montreal.

KEYwORDS: soccer, ice hockey, Portuguese immigrant descendants, Canada, identity.

SARDINHA, João (jmssardinha@gmail.com) - Centro de Estudos das Migrações e das Relações Interculturais (CEMRI), Universidade Aberta, Portugal 


\section{A 4 DE SETEMBRO DE 1983, A ESTAÇÃO DE RÁdiO DE COBERTURA} nacional Canadian Broadcasting Corporation (CBC) transmitiu uma reportagem intitulada "Quando os adeptos do futebol imigram". Com base numa série de jogos que tiveram lugar na cidade de Toronto entre o clube de futebol profissional dessa cidade, o Toronto Blizzard, e duas grandes equipas europeias - o S. L. Benfica de Portugal e a Juventus de Itália -, e durante os quais os espetadores aclamaram com mais energia as equipas visitantes do que o clube da casa, a reportagem radiofónica propôs-se analisar as seguintes questões: $\mathrm{O}$ que acontece quando os adeptos do futebol imigram? Será que trocam também de lealdades clubistas? Ou permanecem ferozmente fiéis às mesmas? Para estes imigrantes, uma visita do clube preferido do seu país natal para um recontro com uma equipa local canadiana é mais do que um simples jogo. Por um lado, é uma ocasião para a demonstração de nacionalismo e de lealdade étnica, bem como uma oportunidade para mostrar que "nós", imigrantes, somos superiores a "vós", canadianos, nesta atividade específica - o futebol. Por outro lado, contudo, é também uma viagem ao passado e às memórias felizes da infância - a um tempo em que iam ao futebol com os pais e em que os heróis desportivos eram "maiores do que a vida" nos seus países de origem. "As antigas paixões ainda pulsam com força no coração do imigrante", explicava o repórter, "não é fácil esquecer as velhas lealdades".

Em Toronto, bem como noutras cidades canadianas, os adeptos do futebol têm ignorado os clubes profissionais locais, já que, como referido na mesma reportagem radiofónica, muitos deles permanecem "sobretudo ligados a clubes europeus, e souberam transmitir aos filhos essas lealdades". Evidentemente, os imigrantes de primeira geração têm laços mais fortes com os seus países de origem - foi aí que nasceram, cresceram, estudaram, trabalharam e, em muitos casos, foi também aí que casaram e constituíram família antes de emigrarem. Mas e quanto aos descendentes desses imigrantes? Quais as suas lealdades? Que variantes participam na formação das suas identidades? Como já referimos, para os imigrantes de primeira geração, a "nova equipa" representativa da "nova cidade" não pode substituir os sentimentos de paixão e os momentos de alegria proporcionados pelas equipas do velho país, às quais estão afetivamente ligados desde a mais tenra infância. Porém, a situação dos seus descendentes é diferente. Neste caso, falamos de indivíduos que cresceram num "ambiente norte-americano", praticando e assistindo a modalidades desportivas que os seus pais nem sequer conheciam antes de imigrarem (por exemplo, o hóquei no gelo, o futebol americano, o beisebol). É, pois, essencial determinar em que medida diferem as lealdades desportivas dos descendentes dos imigrantes, bem como definir o papel que os novos passatempos desportivos desempenham no processo de formação de identidade desta população específica.

O presente artigo visa examinar estas questões através da análise das lealdades e adesões desportivas, bem como do consumo e prática de desportos, entre 
os descendentes de imigrantes portugueses no Canadá. Além disso, debruçar-me-ei sobre os processos de formação e negociação da identidade através dos dois desportos mais populares em ambos os países - o futebol, no caso de Portugal; o hóquei no gelo, no caso do Canadá.

As conclusões apresentadas neste artigo baseiam-se numa pesquisa etnográfica que explorou as narrativas de imigrantes portugueses de geração 1,5 e de segunda geração, de modo a explicitar as conceções e construções de identidade deste grupo particular através das referidas modalidades desportivas. ${ }^{1}$ Os dados empíricos recolhidos mediante entrevistas semiestruturadas e conversas informais com luso-canadianos de geração 1,5 e segunda geração durante o período de trabalho de campo, que decorreu entre 2 de outubro e 5 de novembro de 2009 nas cidades canadianas de Toronto, Otava-Gatineau e Montreal, constituem assim a base da análise aqui apresentada. ${ }^{2}$ No total foram realizadas 30 entrevistas, $15 \mathrm{com}$ participantes do sexo feminino e outras 15 com participantes do sexo masculino, cujas idades iam dos 18 aos 59 anos na altura da realização do trabalho de campo.

\section{O "JOGO CANADIANO" (HÓQUEI NO GELO) VERSUS O "JOGO DOS IMIGRANTES" (FUTEBOL)}

A história desportiva canadiana revela que, ao contrário de outras regióes do antigo Império Britânico (Austrália, Nova Zelândia, o subcontinente indiano, África do Sul e algumas partes das Índias Ocidentais), o Canadá logrou resistir desde muito cedo ao imperialismo desportivo (Metcalfe 1987). A principal razão para o facto é a sua proximidade geográfica com os Estados Unidos, que rejeitaram o controlo político britânico e, desse modo, puderam desenvolver a sua própria identidade desportiva. Por seu turno, os canadianos começaram a interessar-se pelo passatempo desportivo mais popular dos seus vizinhos do sul, o beisebol, que começaram a praticar. O futebol americano também tem uma versão própria no Canadá - o futebol canadiano -, que é similar ao

l A geração 1,5 é constituída por indivíduos de naturalidade portuguesa que emigraram para o Canadá enquanto crianças (com 12 anos ou menos). A segunda geração compreende os indivíduos que nasceram já no país de imigração dos seus pais. No entanto, esta definição não é unânime na literatura especializada, já que muitos investigadores incluem também na mesma categoria aqueles indivíduos que imigraram juntamente com os pais enquanto crianças. Para uma perspetiva geral sobre o conceito de segunda geração e as suas diversas aplicações, veja-se King e Christou (2008: 5-6).

2 De modo a obter uma perspetiva abrangente de opiniões e experiências e a garantir riqueza analítica, foram tomadas em consideração duas importantes dimensões de variação: um equilíbrio homem/mulher e uma representação etária alargada (à época das entrevistas, os participantes variavam entre os 18 e os 59 anos de idade). Os participantes foram recrutados sobretudo por meio de um processo de "boca a boca" (efeito bola de neve) e através de contactos com organizações de imigrantes portugueses antes do início do trabalho de campo. 
seu primo americano, mas apresenta algumas regras diferentes. Além disso, o basquete, um desporto inventado por um canadiano residente nos EUA, é também amplamente praticado no Canadá de hoje. ${ }^{3}$ Porém, se perguntarmos a um canadiano qual o desporto nacional do seu país, a resposta será indubitavelmente "hóquei no gelo", já que, como bem sabe qualquer residente desse vasto país do Norte, essa modalidade desportiva foi inventada pelos canadianos (Bairner 2001). Consequentemente, no Canadá, o hóquei no gelo surge com frequência associado à própria ideia de "canadianidade" [Canadianess] (Gruneau e Whitson 1994; Earle 2002). Bairner (2001: 124) faz notar que "juntamente com a folha de plátano, a Real Polícia Montada e a vida selvagem nativa, o hóquei constitui uma das mais comuns representações da identidade canadiana". ${ }^{4}$

Além disso, segundo Podnieks (1996: 3), "É um facto simples e evidente que, no Canadá, o hóquei toca virtualmente toda a gente, de modo direto ou indireto". Apesar das diferentes ondas migratórias para o Canadá, este desporto tem mantido firmemente o seu estatuto de "jogo nacional do Canadá", sem ser jamais suplantado por outras modalidades e culturas desportivas oriundas de outros países. No caso dos luso-canadianos, conhecemos exemplos de assimilação ao "jogo canadiano" através dos descendentes dos imigrantes, alguns dos quais são hoje jogadores profissionais da NHL. É o caso de Manny Fernandez (Dallas Stars, Minnesota Wild, Boston Bruins), de Mike Ribeiro (Montreal Canadiens, Dallas Stars) e de John Tavares (New Iorque Islanders). ${ }^{5}$ Nestes casos, porém, estamos a falar de luso-canadianos de segunda ou terceira geração, nascidos e educados no Canadá. Assim, a afirmação de Podnieks de que o hóquei "toca virtualmente toda a gente" é verdadeira no sentido em que esse desporto faz parte da cultura de massas canadiana. Porém, tal argumento pode ser contestado se tomarmos em consideração os imigrantes recém-chegados que desconhecem o jogo. Como defende Bairner:

3 O Canadá tem uma equipa profissional de beisebol na Major League americana (os Toronto Blue Jays) e uma equipa profissional de basquete na National Basketball Association ou NBA (os Toronto Raptors); já o futebol canadiano possui a sua própria liga de oito equipas.

4 Embora apenas seis equipas canadianas de hóquei no gelo joguem na liga norte-americana de hóquei, a National Hockey League (NHL) - a saber, os Vancouver Canucks, os Edmonton Oilers, os Calgary Flames, os Toronto Maple Leafs, os Ottawa Senators e os Montreal Canadiens -, a mera presença de canadianos nesta liga é digna de referência. Na temporada de 2008/2009, 52\% dos jogadores da NHL, uma liga constituída por trinta equipas, eram de naturalidade canadiana (informação obtida em <http://www.fromtherink.com/2008/1 l/26/673622/the-nhl-by-nationality-52>).

5 Um tio do jogador da NHL John Tavares, que tem o mesmo nome que ele, é considerado por muitos como o melhor jogador de lacrosse de todos os tempos. O lacrosse é um desporto nativo tradicional que em 1994 foi declarado "desporto nacional de verão do Canadá", através da Lei do Desporto Nacional (Decreto-Lei C-212). 
“É pouco provável que os canadianos mais recentemente chegados ao país procurem confirmar a sua nova identidade nacional através da prática do hóquei no gelo. Ao trazerem consigo as tradições desportivas dos seus países de origem, eles permanecem indiferentes às atrações dessa modalidade. $\mathrm{O}$ futebol e até o críquete constituem opções mais prováveis, o que coloca os novos canadianos em oposição a uma cultura nacional que rejeitou estes desportos no processo de formação de uma identidade própria" (2001: 129).

Isto levanta a questão de saber se a supremacia do "jogo canadiano" está de facto em risco ou se, como aconteceu com as anteriores vagas de imigrantes (incluindo os portugueses), os novos recém-chegados conseguirão adaptar-se à nova cultura e "apaixonar-se" pelo desporto nacional do Canadá.

No que concerne ao futebol, este desporto foi introduzido no Canadá pelos britânicos, e a partida de futebol mais antiga de que há registo é de 1859 (Ronald 2007). Contudo, na apropriação de desportos populares britânicos por parte dos nativos canadianos, o futebol nunca alcançou grande popularidade ou visibilidade. Ao longo do século XX, com o influxo de diferentes grupos de imigrantes, a prática do futebol foi sobretudo mantida por estes recém-chegados. O facto levou a que esse desporto fosse muitas vezes denominado como "o jogo estrangeiro" (Hay 2006), já que são sobretudo os imigrantes e seus descendentes que manifestam um maior entusiasmo pelo mesmo.

No Canadá, a popularidade do futebol tem oscilado ao longo dos anos, mas esta modalidade nunca conseguiu suplantar qualquer outro dos desportos mais apreciados na América do Norte, sobretudo no que toca à base de adeptos. Tem surgido ao longo dos anos uma série de ligas profissionais e semiprofissionais de futebol. A primeira foi a canadiana National Soccer League (NSL), cujas equipas eram, na sua maioria, de base étnica. ${ }^{6}$ A First Portuguese de Toronto é um exemplo disso. Na esteira de um aumento de popularidade do jogo após a transmissão global do Mundial de 1966, empreenderam-se esforços no sentido de criar uma liga transfronteiriça (Canadá/EUA) similar às que existiam no âmbito do beisebol, do basquete e do hóquei no gelo. Assim nasceu, em 1968, a Liga Norte-Americana de Futebol (North American Soccer League - NASL). Ao longo dos anos 70 e 80, o Canadá esteve representado na NASL por equipas de cidades como Montreal, Toronto, Calgary, Edmonton e Vancouver. Devido à baixa popularidade do jogo, bem como a uma fraca gestão das equipas e da liga, a NASL foi extinta em 1985. Porém, durante esse período, com as equipas de futebol norte-americanas a oferecem contratos milionários a jogadores europeus, duas das maiores estrelas do futebol português, Eusébio 
e Matateu, integraram equipas canadianas - Eusébio jogou no Metro-Croatia de Toronto, uma equipa da NASL, em 1976, e Matateu na First Portuguese em 1970. ${ }^{7}$ A única participação do Canadá no Mundial de Futebol ocorreu em 1986, no México. No seguimento dessa participação, e com o objetivo de substituir a defunta NASL, fundou-se em 1987 a Canadian Soccer League (CSL), que duraria até 1992. Um ano após a extinção desta, três equipas que tinham sobrevivido tanto à NASL como à CSL - Toronto Blizzard, Vancouver Whitecaps (conhecidos como os "86ers" na CSL) e Montreal Impact - aderiram à A-League dos Estados Unidos, que em 2004 seria rebatizada como United Soccer League (USL). Por fim, em 2007, o recém-criado Toronto FC (que veio substituir o Toronto Blizzard) aderiu à Major League Soccer (MLS), constituindo o seu primeiro franchise fora dos Estados Unidos. As duas equipas canadianas da USL - Vancouver Whitecaps e Montreal Impact - juntar-se-ão ao Toronto FC na MLS em 2011 e 2012, respetivamente.

Contudo, embora não seja uma modalidade desportiva de grande dimensão em termos de base de adeptos, assistência aos jogos e profissionalismo, o futebol é, surpreendentemente, o desporto com o mais elevado número de praticantes amadores no Canadá - de facto, a partir da década de 1980, o futebol suplantou lenta mas decididamente o hóquei no gelo como desporto com o maior número de jogadores registados no país. Em 2005 havia 841.466 jogadores de futebol, contra os 543.390 jogadores de hóquei registados no Canadá (Ifedi 2005).

Assim como outros imigrantes, os portugueses contribuíram para a crescente popularidade do futebol no Canadá, sobretudo através da criação de equipas ao nível amador e recreativo. Embora não existam números oficiais, sabe-se que um grande número de homens e mulheres portugueses e luso-canadianos de todas as idades praticam futebol ao nível amador neste país. A prova está, por exemplo, no número de equipas de futebol ligadas a associações portuguesas, bem como no número de equipas portuguesas (e muitas vezes com nomes portugueses) presentes em diversas ligas recreativas de todo o Canadá. ${ }^{8}$

Além destas oportunidades dadas aos jovens para a prática do futebol, as diferentes ligas profissionais e semiprofissionais do Canadá têm proporcionado aos luso-descendentes a possibilidade de desenvolverem as suas capacidades enquanto "futebolistas" numa nação onde esta modalidade desportiva não se reveste de particular importância. Já referimos que nos anos 70 dois dos maiores

7 Matateu jogaria depois, entre 1972 e 1982, no Sagres Victoria, uma equipa amadora da cidade de Victoria, na Colúmbia Britânica (Correia 2006).

8 Para esta trabalho de investigação, foram também estudadas a Canadian Multicultural Soccer League, uma liga masculina de futebol sénior sediada em Toronto, cujo grupo étnico mais representado é o dos portugueses ou luso-descendentes, e que integra uma série de equipas portuguesas (ver $<$ http://www. hometeamsonline.com/teams/?u=FCPWOODBRIDGESOCCER\&s=soccer\&t=c $>$ ), e o FC Unidos, um clube de futebol português multietário sediado em Gatineau (ver <http://www.fcunidos.com>). 
vultos do futebol português exerceram os seus talentos no Canadá, e, mais recentemente, este país tem facultado estruturas e espaços onde os descendentes de imigrantes portugueses podem aperfeiçoar as suas capacidades e crescer enquanto jogadores, de tal forma que alguns chegam mesmo a integrar equipas de futebol portuguesas ou até a seleção nacional. Foi o caso, por exemplo, de Steven Vitória (desde 2006: F.C. Porto, G.D. Tourizense, S.C. Olhanense, Sporting da Covilhã, G. D. Estoril Praia e seleções nacionais jovens), de Daniel Fernandes (desde 2006: seleção nacional A), ou de Fernando Aguiar (entre 1994 e 2009: C. S. Marítimo, Nacional da Madeira, F. C. Maia, S. C. Beira-Mar, S. L. Benfica, União de Leiria, F.C. Penafiel, Gondomar S. C.), no futebol masculino, e de Alexandra Valério (desde 2009: seleção nacional A), no futebol feminino. No contexto do futebol profissional canadiano, igualmente digno de nota é o facto de que dois treinadores portugueses têm dirigido alguns dos clubes profissionais do país: Tony Fonseca, antigo internacional português que fixou residência no Canadá, treinou o Vancouver Whitecaps F.C. durante três temporadas, entre 2002 e 2004; e o atual treinador do Montreal Impact é o luso-descendente Marc dos Santos.

No que diz respeito à base de adeptos e à assistência aos jogos, e como ficou patente na reportagem radiofónica da CBC "Quando os adeptos do futebol imigram" referida no início deste artigo, o futebol português reveste-se da mais alta importância para os imigrantes portugueses. A prova disto está na existência de "casas" e núcleos de adeptos de clubes de futebol portugueses em várias cidades canadianas. Nas cidades de Toronto e Montreal, por exemplo, não só estão presentes as três grandes equipas portuguesas - F.C. Porto, S.L. Benfica e Sporting C.P. -, como também o Vitória de Setúbal, o Gil Vicente F.C., o Varzim S.C., o C.D. Santa Clara, entre outras. Ademais, as associações portuguesas, além de constituírem uma força fundamental por detrás da preservação da cultura portuguesa e de organizarem todo o tipo de atividades dentro da comunidade luso-canadiana (criação de ranchos folclóricos, organização de festividades tradicionais portuguesas, etc.), podem também equipar as suas instalações com televisão por cabo ou satélite, de modo a sintonizarem os jogos de futebol de canais portugueses como a RTPi, por exemplo. O mesmo acontece em muitos cafés e bares portugueses, ainda que estes não se encontrem em todas as cidades canadianas.

Porém, para os portugueses que vivem atualmente no Canadá, a ligação ao futebol português pode ser estabelecida com um simples "clique", através das novas tecnologias da informação. A Internet permite a estes adeptos manterem-se a par dos jogos dos seus clubes preferidos em tempo real. Alguns dos meus entrevistados aludiram a um tempo em que era necessário esperar quatro, cinco ou seis dias para receberem um diário desportivo português com informações que tinham quase uma semana de atraso. Hoje em dia, a globalização do desporto, com a ajuda das novas tecnologias, pode desempenhar um papel 
importante na definição da identidade, proporcionando outras alternativas aos adeptos (Maguire 1999). Na secção seguinte, analisarei o modo como os descendentes de emigrantes portugueses no Canadá negociam as suas identidades através dos desportos mais populares dos dois países que partilham.

\section{DEFINIR IDENTIDADES ATRAVÉS DO HÓQUEI NO GELO CANADIANO E DA ADESÃO AO FUTEBOL PORTUGUÊS}

Em certas etapas da vida podemos deparar com contextos espaciotemporais nos quais transcendemos fronteiras identitárias em busca de identificações transeccionais (Christou 2004). Na formação e negociação de identidades, estes ajustamentos de identificação transeccional constituem um fenómeno comum. Para os descendentes de migrantes, em particular, tais construções assumem frequentemente o caráter de "guerras culturais" (Nunes 1995). Tendo crescido no país de emigração dos seus pais, os indivíduos desta população específica são definidos por padrões de vida pluralistas e biculturais, resultantes de um processo de bissocialização que envolve duas esferas: a "interna" - o espaço étnico e sociocultural vivido principalmente dentro da unidade familiar e da comunidade étnica - e a "externa" - o espaço exterior à primeira (Gokalp 1988).

Na esfera interna, sobretudo dominada pelo ambiente doméstico e pelas relações no seio da comunidade étnica, se a autoridade parental persiste, se a vida doméstica é mantida dentro de padrões tão étnicos quanto possível (linguagem, comida, meios de comunicação, hábitos, etc.) e se existem recursos étnicos para ajudar os descendentes a permanecerem imersos na sua cultura de origem (incluindo fortes laços institucionais étnicos mantidos por meio da participação em atividades associativas ou religiosas, da escolaridade em língua portuguesa, de visitas frequentes ao país de origem, entre outros fatores), a aculturação torna-se muito mais difícil. O capital social das famílias e da comunidade étnica torna-se assim fundamental na manutenção da filiação étnica. Por outro lado, o indivíduo tem também uma vida fora dos círculos étnicos que desempenha um papel importante no distanciamento étnico. A escola torna-se o primeiro bastião desta rotura, já que é aqui que decorre a maior parte da vida durante a infância e a adolescência; mais tarde será substituída pelo ambiente de trabalho.

Para os descendentes de migrantes torna-se evidente, desde a mais tenra idade, uma coexistência intercultural dominada por uma relação sociocultural entre as duas esferas referidas. Em diferentes momentos e espaços da vida desses indivíduos, os dois campos assumirão diferentes graus de significado e importância. Esta dicotomia "externa/interna" é muitas vezes duradoura, delimitada por fronteiras de envolvimento rígidas. Assim, as duas esferas estão sempre ativas, com negociações constantes de relações e envolvimentos (por exemplo, dominação/submissão, parceria/oposição, reconhecimento/estranheza, etc.) 
que se opõem uns aos outros. É precisamente no seio desta multiterritorialidade sociocultural que a identidade dos luso-descendentes se joga, tornando-se o resultado de uma construção ao longo do tempo e do espaço. As duas esferas socioculturais exigem que o indivíduo se enquadre num dos espaços e que rejeite ou ignore todas as experiências, construções e relações que ocorrem frequentemente na interseção dessas mesmas esferas. Se não o fizer, o indivíduo achar-se-á numa posição de estrangeiro ou de minoria, e portanto mais suscetível à subordinação e à exclusão.

Para os descendentes de migrantes, a formação de identidade torna-se assim um recurso a ser moldado com vista ao favorecimento da sua inclusão social. Pang (2000) utiliza a expressão "etnicidade como arma" ao descrever a natureza elástica da identidade étnica, no sentido em que os principais agentes pertencentes a minorias étnicas estão frequentemente envolvidos em constantes negociações consigo mesmos e com o(s) grupo(s) maioritário(s) de uma dada sociedade. Em resposta às forças gerais da sociedade no seu todo, estes indivíduos alteram com frequência a sua identidade étnica ou adaptam elementos do grupo maioritário com vista à sua inserção no mesmo. Para aqueles que estão particularmente interessados em gozar de todos os benefícios de uma sociedade exterior às normas e características do seu grupo étnico particular, uma identidade étnica pode revelar-se pouco atrativa. Assim como o camaleão, que muda de cor para melhor se confundir com o meio envolvente, também estes indivíduos fazem por se adaptar à cultura dominante do país onde vivem (Cunha 1988).

Deste modo, ainda que a etnicidade signifique que um indivíduo partilha certas qualidades, características ou costumes com um grupo étnico específico, a identidade étnica é multifacetada, fluida e, mais importante ainda, pessoal. Assim, hipoteticamente, um indivíduo pode nascer no Canadá, filho de pais portugueses. Pode comer comida portuguesa com regularidade, já que é o tipo de comida que se cozinha lá em casa. Pode não ter frequentado uma escola portuguesa nem conseguir manter uma conversa nessa língua - mas, ainda assim, ele celebra as festividades tradicionais portuguesas juntamente com os membros da comunidade portuguesa da sua cidade, bem como as festividades canadianas. Em termos de nacionalidade, ele pode ser canadiano ou possuir dupla nacionalidade - mas a questão é: que etnicidade é a sua? É canadiano? Português? Ambas as coisas? Bom, isso dependerá de uma série de fatores. Em primeiro lugar, a identificação é imposta por si próprio ou pelos outros? Em segundo lugar, o que está em jogo na construção dessa identidade? E, em terceiro lugar, a propensão para assumir uma identidade portuguesa ou canadiana num determinado momento é condicionada por um acontecimento ou ocorrência exteriores?

Como fizeram notar diversos investigadores (Nunes 1986; Oliveira e Teixeira 2004a, 2004b; Noivo 2002; Trindade 2007), a maioria dos descendentes luso-canadianos recai numa categoria de identidade intermédia, habitando um mundo de contradições étnicas/nacionalistas na definição do eu. Estamos 
perante uma população que sente a necessidade de valorizar positivamente a sua identidade portuguesa e de a ver valorizada pelos outros - consequentemente, a maioria dos luso-canadianos fala com orgulho da sua identidade e cultura portuguesas. Ironicamente, como referiram vários dos indivíduos que entrevistei no Canadá, muitos luso-canadianos "não praticam o que dizem", já que não participam na vida das suas "comunidades", e sentem muitas vezes embaraço em falar português fora da comunidade, ou não veem benefícios em fazê-lo dentro da mesma (Oliveira e Teixeira 2004a: 209-210). Isto deve-se sobretudo a algo a que Suárez-Orozco (2000) chama "espelhamento social" (social mirroring), um processo que ocorre em tenra idade e pelo qual os descendentes de migrantes se comparam com o meio circundante, estabelecendo semelhanças ou dissemelhanças sociais em relação aos grupos de referência. Deste modo, participar em atividades étnicas de caráter comunitário é entendido pela maioria como uma desvantagem em termos de estatuto social, já que os seus pares não étnicos não praticam um estilo de vida similar.

Porém, as contradições não acabam aqui. Se bem que, na sua maioria, os descendentes luso-canadianos sintam que fazem parte da cultura dominante, isto não cerceia a sua identidade portuguesa, já que, tendo crescido no seio de uma família portuguesa e de um ambiente cultural específico, as pressões a que foram sujeitos para preservarem a sua cultura de origem contribuíram para o desenvolvimento de uma clara e permanente consciência étnica (Oliveira s.d.; Oliveira e Teixeira 2004a, 2004b). Tudo o que os rodeia aponta nessa mesma direção: os pais que lhes falam em português e de Portugal, os professores, os líderes da comunidade, os meios de comunicação e até a política multicultural canadiana. Tudo isso lhes recorda que é importante preservarem as suas "raízes" e o orgulho de serem portugueses. E mesmo na escola ou no trabalho, os amigos e colegas referem-se a eles como "portugueses" e não como "canadianos" - que é o que a maioria deles é.

Principalmente no caso dos jovens luso-descendentes do sexo masculino, como confirmado por muitos dos indivíduos com quem falei durante o meu trabalho de campo no Canadá, o desporto constitui uma via para a integração e a aceitação. Porém, durante a infância e a adolescência, não é o amor ao futebol português que permite tal integração e aceitação. São antes as partidas de hóquei que se jogam na rua com os miúdos da vizinhança; é a paixão sentida e partilhada com amigos pela equipa local da NHL e seus jogadores; são as coleções de cromos de hóquei no gelo e a assistência ao programa televisivo Hockey Night in Canada todas as noites de sábado. ${ }^{9}$ Tudo isto permite

9 O Hockey Night in Canada é um programa que transmite os jogos da National Hockey League, na qual participam equipas sediadas no Canadá, e que é emitido desde 1952. Tem sido desde sempre um dos programas de maior audiência da televisão canadiana e é o mais antigo programa desportivo do país. É considerado uma instituição cultural canadiana. 
a muitos jovens luso-descendentes serem como os outros miúdos canadianos, participarem nas conversas e estarem tão atualizados como os seus pares num tópico de grande popularidade e aceitação. Alguns indivíduos com quem falei em Toronto e Montreal referiram a sua devoção pelos Toronto Maple Leafs e os Montreal Canadiens, as duas equipas históricas do hóquei no gelo canadiano, comparando-as em importância e legado aos dois grandes clubes de futebol lisboetas: o S. L. Benfica e o Sporting C.P.

O exemplo acima referido evoca a conceção positiva e esperançosa do hóquei no gelo, apresentando-o como inestimável à promoção da integração social e cultural e, desse modo, à unidade nacional (Field 2000). Bairner (2001: 125) faz notar que, no Canadá, o hóquei no gelo ajuda a lidar com a questão da divisão interna, funcionando de molde a consolidar a diferença entre o Canadá francês e o Canadá inglês. Porém, como já demonstrámos, isto transcende os dois grandes grupos canadianos, ajudando a integrar também os descendentes de imigrantes. Nesta perspetiva, o hóquei no gelo é comparável a um modo de socialização que, ao apresentar aos imigrantes os valores culturais e as preferências sociais da sociedade anfitriã, lhes oferece um meio informal mas potente de conseguirem mobilidade social através da assimilação cultural (Dyck 2007). Contrariamente, a falta de envolvimento ou participação no passatempo desportivo mais popular do país anfitrião pode ser interpretada como um esforço efetivo de manter uma distinção e separação cultural dentro da sociedade canadiana. De facto, para os imigrantes portugueses e seus descendentes, seguir o futebol português e dar mostras desse interesse, ao invés de aderirem aos desportos favorecidos no seu "novo" país, pode ser entendido como um ato deliberado de delineação de uma fronteira, por meio do qual se estabelecem limites à inserção no novo ambiente e se favorece uma desejada segregação (Figueroa 2003; Dyck 2007).

Assim, as questões de pertença figuram predominantemente no caso dos descendentes de migrantes que estão integrados no tempo e espaço reais do ambiente onde residem e que podem assumir uma identidade nacional canadiana, ao mesmo tempo que transportam o peso da ancestralidade e da tradição étnica. Estes indivíduos desafiam frequentemente os modos como são vistos "enquanto outros" pelos seus pares canadianos, que entendem uma identidade nacional anglo-francófona como o resultado final e acreditam que o ser-se diferente e identificar-se com elementos da sua própria etnicidade não equivale de modo algum a um desejo de se ser não canadiano (un-Canadian). Jorge, ${ }^{10}$ um entrevistado de 33 anos de Montreal, definiu do seguinte modo esta dupla representação, recorrendo a elementos característicos do Canadá e de Portugal para se autodefinir: 
"Posso ser canadiano - o hóquei [no gelo], a cerveja, os invernos frios e a neve fazem parte de mim tanto como de qualquer outro que se afirme mais canadiano do que eu. A questão é que eu sou algo mais do que isso. Por cada jogo de hóquei [no gelo], por cada cerveja, por cada inverno, há uma outra parte de mim que me é igualmente importante: o futebol, o vinho e os dias de sol na praia - coisas portuguesas. Ora bem, se eu assisto a um jogo de hóquei [no gelo] e bebo cerveja... Hei, isso é canadiano! Mas se assisto a um jogo de futebol e bebo vinho, isso já não é considerado tão canadiano assim".

No seu estudo pioneiro sobre os processos identitários dos descendentes luso-canadianos, Nunes (1986) defende que esta população se debate com importantes questões de autodefinição no que toca à formação da sua identidade. Segundo o autor, o resultado final é muitas vezes uma construção de identificação que conduz à criação de um "terceiro espaço" (Bhabha 1994), um espaço que não é nem canadiano nem português, mas antes uma combinação de ambos. O depoimento de Jorge exemplifica a aceitação de elementos culturais do "ser-se português" e do "ser-se canadiano", um processo no qual tanto o futebol (português) como o hóquei no gelo (canadiano) constituem elementos chave. O resultado final é um misto que integra elementos de ambos os campos, pelo que o indivíduo não se vê forçado a escolher entre um e outro, criando em vez disso um "terceiro espaço".

De acordo com Bulger (1987), porém, o principal problema desta relação dual é a "indecisão" quanto à conveniência de se assumir uma ou outra identidade - portuguesa ou canadiana. Esta escolha, como explica o autor, "requer a competência de um acrobata na corda bamba, mesmo para aqueles que estão parcialmente integrados e que adotaram as características que admiram de ambos os mundos, ao mesmo tempo que rejeitaram os aspetos que lhes desagradam" (Bulger 1987: 11). Partindo do mesmo argumento, Trindade (2007) defende que as formações e construções identitárias de pertença dependem dos seus custos e benefícios para um determinado grupo. José, um luso-canadiano de Toronto com 30 anos, descreveu esta negociação do seguinte modo:

"Há que saber jogar as cartas certas. Temos de ter em atenção aquilo que dizemos e não dizemos, aquilo que fazemos e não fazemos. Há um tempo certo e um lugar certo para tudo. Por exemplo, não vou me pôr a dizer aos canadianos que a minha cultura é melhor do que a deles. Há certas pessoas que gostam de exibir a sua portuguesidade a toda a hora e momento, como por exemplo aqueles que vestem uma camisola do Benfica para irem assistir a um jogo dos [Toronto Maple] Leafs. Isso não faz sentido nenhum".

As estratégias de formação de identidade dos luso-canadianos serão pensadas e moldadas de acordo com o modo como os outros "os veem". No seu 
depoimento, José sugere que os descendentes de imigrantes portugueses deveriam adotar a estratégia do "tempo e lugar certos", pela qual as manifestações públicas de "portuguesidade" deveriam começar por ser avaliadas quanto ao seu grau de adequação em contextos não portugueses. Deste modo, a problematização do tempo e lugar "certos" para as afirmações de identidade portuguesa poderá encontrar uma resposta mais cabal através de uma outra questão: o que há a ganhar? Os luso-descendentes podem preferir distanciar-se de determinados elementos da identidade portuguesa - como, por exemplo, o futebol português -, se sentirem que tal identificação constitui um obstáculo potencial à sua mobilidade na sociedade canadiana. Porém, inversamente, nos casos em que o "ser-se português" é entendido como um recurso para a promoção social, os luso-canadianos optarão provavelmente por se aproximarem e por explorarem esses elementos étnicos.

A questão é saber quais as variáveis presentes nos processos identitários desta população, e quais as variáveis que não estão envolvidas na sua capacidade de "escolher" aquilo que mais lhes convém sem perturbar o equilíbrio de aceitação por parte da sociedade dominante (Klimt 2002). Porém, o que diferencia os luso-canadianos dos "canadianos comuns" (mainstream Canadians) são as marcadas expressões, manifestações e representações etnoculturais de portuguesidade (Anderson e Higgs 1976; Higgs 1990; Teixeira e Da Rosa 2000; Giles 2002; Gomes 2008). Para os luso-descendentes, estes aspetos estão quotidianamente presentes, seja em casa, através da comunidade portuguesa, seja através do olhar dos outros que assim os identificam. As minhas conversas com luso-descendentes no Canadá revelaram que as expressões de portuguesidade (Gomes 2008) são ativadas enquanto estratégias com vista a identificar o indivíduo como português ou, pelo contrário, desativadas, nos casos em que o indivíduo prefere desvincular-se dessa descrição e identificação. Isto pode incluir atos como falar português em público, frequentar uma escola portuguesa, participar num rancho folclórico, manter relações de amizade com outros portugueses, ou, pelo contrário, evitar todas essas estratégias. Tais opções permitem aos indivíduos desta população navegar livremente entre culturas sem que lhes sejam impostos rótulos estereotipados.

Oliveira e Teixeira (2004a) observam que os indicadores escolhidos pelos descendentes luso-canadianos para justificarem o seu orgulho étnico português são meramente simbólicos (históricos, culturais, etc.), permitindo-lhes escapar a quaisquer posições ou comparações desfavoráveis com a sociedade anfitriã. Perante isto, não nos surpreende que os luso-descendentes entrevistados apontem o futebol português como o elemento que lhes proporciona mais orgulho das suas raízes portuguesas. O facto é particularmente notório no caso da seleção portuguesa e do sucesso de alguns jogadores de futebol portugueses. Para manifestarem publicamente este sentimento de orgulho, muitos referiram o uso de vestuário alusivo ao futebol português e aos seus jogadores, sobretudo 
quando estes atuam em "palcos mundiais" como o Campeonato Mundial ou o Campeonato Europeu. Quanto a este tópico, Isabel, uma luso-descendente de Toronto com 31 anos, afirma o seguinte:

"Na altura do Mundial [de Futebol] e do Euro [Campeonato Europeu], as pessoas vinham todas festejar para a rua, e toda a gente usava a camisola da seleção. Aqui há todo o tipo de grupos de imigrantes, o que dá azo a rivalidades através do futebol. Mas, nestes últimos anos, jogadores como o [Luís] Figo e o [Cristiano] Ronaldo têm contribuído imenso para uma boa imagem de Portugal, e o futebol [...] com a sua popularidade internacional [...] até mesmo aqui [...] agora usamos as camisolas e veem-se imensas do [Cristiano] Ronaldo, por exemplo, pois as pessoas conhecem-no. É o melhor do mundo e é português e nós queremos que toda a gente saiba disso. Dá-nos uma boa imagem".

De acordo com as palavras de Isabel, a representação étnica revela-se um instrumento de filiação positiva, bem como de competição étnica. Quanto a este tópico, os entrevistados entendem o futebol português, a camisola da seleção nacional e os futebolistas portugueses de renome internacional como características de identidade que merecem visibilidade, uma vez que constituem imagens e personalidades portuguesas valorizadas pelos não portugueses. ${ }^{11} \mathrm{O}$ reconhecimento da portuguesidade através do futebol por parte dos não portugueses é confirmado de modo enfático por Alberto, um luso-canadiano de Otava-Gatineau com 43 anos:

"Quando os nossos pais aqui chegaram e conheciam outras pessoas - pessoas de outros grupos de imigrantes, por exemplo - que lhes perguntavam 'De onde és?' e eles diziam 'Portugal', a única coisa que os outros conheciam de Portugal era o Eusébio: 'És português? Oh, o Eusébio é fantástico!' [...] Atualmente, a geração de hoje tem um novo representante, e vem uma vez mais do futebol: 'Cristiano Ronaldo isto, Cristiano Ronaldo aquilo...' Goste-se ou não dele, as pessoas reagem, pois toda a gente o conhece. Ele é a cara de Portugal".

11 Porém, esta filiação étnica positiva através de personalidades internacionalmente conhecidas não é exclusiva do futebol. No seu estudo, Pacheco (2004) chega a conclusões semelhantes relativamente à imagem de Nelly Furtado, enfatizando que o sucesso internacional da cantora tornou sexy um tipo particular de euro-portuguesidade. Tendo em conta que Furtado alcançou renome internacional sem deixar de afirmar as suas raízes portuguesas, a promoção da etnicidade da cantora funciona de molde a lançar uma luz positiva sobre os luso-descendentes, em particular as jovens mulheres, que acabam por ser positivamente estereotipadas pela sua associação étnica com a cantora luso-canadiana (Pacheco 2004: 90). 
Quanto à narrativa de Alberto, dois aspetos adicionais merecem maior atenção: em primeiro lugar, a afirmação da identidade portuguesa através do futebol é um fator que transcende gerações e, para os portugueses, uma vez fora de Portugal e entre indivíduos de outras etnias, o futebol português constitui uma variável de reconhecimento positiva e bem acolhida. Em segundo lugar, como sugerido por Jarvie (2006), a identidade permite a uma pessoa constituir-se como sujeito individual: 1) através do autorreconhecimento; 2) ao ser reconhecido por outro sujeito ou grupo. Nesta perspetiva, o reconhecimento por meio do desporto (no caso que aqui nos ocupa, o futebol) é mobilizado enquanto estratégia potencial em situações de deslocamento geográfico do grupo ou de posicionamento minoritário, por meio de uma ação afirmativa que desafia as imagens pejorativas ou depreciativas do grupo em questão (Jarvie 2006: 287). Assim, quaisquer imagens ou estereótipos negativos que possam existir em relação aos portugueses são contrabalançados por estereótipos positivos de excelência e valor através de personalidades bem-sucedidas do futebol português ou praticado em Portugal.

Ora bem, num país multicultural como o Canadá, constituído em grande parte por pessoas oriundas de diferentes partes do mundo, há certos fatores óbvios que influenciam mais do que outros a identidade étnica. De acordo com Wever-Rabehl (2006), nenhum outro fator além do futebol permite uma identificação tão imediata dos migrantes com as suas raízes étnicas. Wever-Rabehl, uma investigadora canadiana de ascendência holandesa, escreve sobre os seus próprios sentimentos: "Embora eu me veja a mim própria como canadiana, este facto muda rapidamente durante o Mundial de Futebol. Quando os Leões Laranja entram em campo, eu sou holandesa". Neste ponto, há que ter em atenção o aspeto temporal deste tipo de nacionalismo suscitado pelo futebol. No depoimento que citámos atrás, Isabel refere também que, aquando do Mundial e do Campeonato Europeu, os portugueses enchiam as ruas de Toronto para celebrarem as vitórias da seleção nacional. Naturalmente, tal como noutras cidades cosmopolitas com uma grande tradição de migração, não nos espanta minimamente que as comunidades de imigrantes festejem dessa forma os triunfos desportivos dos seus países de origem (Chalip 2006).

Assim, além de proporcionar aos imigrantes e seus descendentes rótulos positivos que reforçam a sua identidade étnica, o futebol é utilizado como uma "arma" na luta pelo reconhecimento, pela promoção e pela obtenção de direitos numa sociedade mais ampla. Nas cidades canadianas, os portugueses competem e rivalizam muitas vezes com outros grupos de imigrantes do Sul da Europa, incluindo (ainda que não exclusivamente) os italianos, os gregos e os croatas. ${ }^{12}$ Os luso-canadianos que entrevistei em Toronto, por exemplo, 
referiram a já antiga rivalidade entre as comunidades portuguesa e italiana, sobretudo devido à proximidade geográfica ("Little Italy" é adjacente a "Little Portugal", a norte) e social entre ambas. Esta disputa, como me foi explicado, é frequentemente acentuada por meio das rivalidades e dos antigos sucessos das respetivas seleções nacionais desses países. Do mesmo modo, a final do Euro 2004 entre Portugal e a Grécia, da qual a Grécia saiu vencedora, constituiu uma oportunidade para ver qual dos grupos étnicos teria o direito de manifestar mais ruidosamente o seu orgulho étnico entre uma população maioritária que pouco tinha que ver com esse último jogo.

Assim, o que é que tudo isto implica? No Canadá multicultural, onde a legislação sobre o multiculturalismo estabelece a pluralidade como norma, apoiar o país de origem e conferir maior importância à herança e às raízes étnicas do que à identidade "canadiana" (Bissoondath 1994; Gwyn 1997) é, em grande medida, um comportamento aceite e normal, sendo certo que existem muito poucas formas de o demonstrar que não através de um desporto como o futebol, o qual de dois em dois anos prende as atenções do mundo e pode assim fornecer notoriedade a determinados grupos étnicos ou países, desde que as seleções que os representam obtenham sucesso nessas competições. Assim, para os luso-descendentes, num país onde a preservação e as manifestações de identidade étnica são encorajadas e onde diferentes grupos étnicos se esforçam para promover a sua etnicidade e diferença, o sucesso futebolístico constitui uma importante via de acesso à ribalta.

\section{CONCLUSÃO: "SEJA FUTEBOL OU HÓQUEI NO GELO, NA MINHA VIDA HÁ ESPAÇO PARA OS DOIS"}

Nos contextos migrantes, a cultura desportiva pode enquadrar a identidade através de uma temporalidade formalizada, atribuindo frequentemente maior importância à herança e à origem do que aos caminhos identitários complexos escolhidos pelos indivíduos no país de imigração. Contudo, as experiências, as ligações afetivas e os sentimentos herdados dos descendentes luso-canadianos sugerem uma interpretação mais crítica, oferecendo novas estruturas identitárias em resposta a processos complexos de interação social, em que o sentido de si pode ser definido e redefinido, assumido em determinados contextos, dissimulado noutros e por vezes utilizado como "arma" com vista à obtenção de notoriedade e até de recursos no seio da sociedade mais alargada. Deste modo, como já vimos, a construção identitária através dos dois desportos aqui analisados é ativamente reconstituída e representada mediante a adoção de uma variedade de identificações e lealdades de diversos graus. No Canadá, os luso-descendentes também se adaptam ao modo de vida canadiano, adotando elementos de ambas as culturas, portuguesa e canadiana. O interesse pelos dois desportos referidos, bem como a participação nos mesmos, prova-o. 
Assim, a adesão e a assistência aos dois desportos nacionais dos respetivos países a que estão ligados acaba por exemplificar o modo como, para esses indivíduos, a formação de identidade e a integração social se tornam um caminho bifurcado.

Nestas estratégias de identidade que envolvem dois desportos, coexistem "dois mundos" igualmente influenciados por filiações territoriais e processos de identificação e aceitação social, bem como por definições impostas pelo "outro" - essas que os identificam como portugueses e que levam muitos a empunhar "armas" étnicas/nacionalistas nos momentos oportunos. Como vimos, não há melhor ocasião para tanto do que o Mundial de Futebol ou o Campeonato Europeu, momentos em que diferentes identidades étnicas se confrontam, envolvendo até reivindicações de direitos. Porém, quando se lhes pede que definam a sua identidade através dos dois desportos, a maioria dos indivíduos recai numa categoria que podemos denominar "identidade hifenizada". Este facto vem confirmar o argumento de que a maioria dos luso-descendentes não possui uma identidade étnica única e claramente definida, mas, pelo contrário, está dividida entre diferentes culturas e diversas lealdades, pelo que a ligação afetiva ao futebol português pode coexistir com sentimentos similares pelo hóquei no gelo canadiano. A expressão "terceiro espaço" (Bhabha 1994) é, pois, uma descrição adequada do espaço que estes indivíduos criam e ocupam.

Lidar com o "hífen" e saber quando posicionar-se num ou noutro dos "dois mundos" são aspetos que exigem ponderação. Possuir um tal conhecimento proporcionará provavelmente o apoio social que torna a adaptação possível. Os descendentes luso-canadianos assumem variáveis passíveis de os favoreceram aos olhos dos seus pares não portugueses, como, por exemplo, a identificação com futebolistas portugueses de renome mundial. Se a sobrevivência é mais importante do que a preservação étnica, então podemos pressupor que estes indivíduos se encontram "no caminho da assimilação", já que a questão chave é a sua inserção na sociedade dominante. As negociações e as contestações desenvolvem-se dentro deste meio - negociações e contestações que desafiam a formação identitária dos luso-descendentes e contribuem para a formação da mesma.

Em suma, para os descendentes dos imigrantes portugueses no Canadá, os dois desportos assumirão diferentes significados em diferentes momentos e espaços, de acordo com a importância, a prática e o consumo de cada um. No Canadá podemos observar que os luso-descendentes estão presentes em ambos os desportos e que ambos os desportos estão presentes nas vidas de muitos luso-descendentes. 


\section{BIBLIOGRAFIA}

ANDERSON, Grace, e David HIGGS, 1976, A Future to Inherit: Portuguese Communities in Canada. Toronto, McClelland and Stewart.

BAIRNER, Alan, 2001, Sport, Nationalism, and Globalization: European and North American Perspectives. Nova Iorque, State University of New York Press.

BHABHA, Homi, 1994, The Location of Culture. Londres, Routledge.

BISSOONDATH, Neil, 1994, Selling Illusions: The Cult of Multiculturalism in Canada. Toronto, Penguin Books.

BULGER, Laura, 1987, Canadianos ou Étnicos? Em Busca de Uma Identidade. Lisboa, Secretaria de Estado das Comunidades Portuguesas.

CHALIP, Laurence, 2006, "Towards social leverage of sport events", Journal of Sport \& Tourism, 11 (2): 109-127.

CHRISTOU, Anastasia, 2004, "Reconceptualizing networks through Greek-American return migration: constructing identities, negotiating the ethnos and mapping diaspora - theoretical challenges regarding empirical contributions", Spaces of Identity, 4 (3): 53-70.

CORreIA, Fernando, 2006, Matateu: A Oitava Maravilha. Lisboa, Sete Caminhos.

CUNHA, Marie, 1988, Portugais de France. Paris, Éditions L'Harmattan.

DYCK, Noel, 2007, "Playing like Canadians: improvising nation and identity through sport", em Simon Coleman e Tamara Kohn (orgs.), The Discipline of Leisure: Embodying Cultures of 'Recreation'. Oxford, Berghahn Books, 109-126.

EARLE, Neil, 2002, "Hockey as Canadian popular culture: team Canada 1972, television and the Canadian identity", em Joan Nicks e Jeannette Sloniowski (orgs.), Slippery Pastimes: Reading the Popular in Canadian Culture. Waterloo, Ontario, Wilfrid Laurier University Press: $321-344$.

ESSES, Victoria, et al., 2001, "The immigration dilemma: the role of perceived group competition, ethnic prejudice, and national identity", Journal of Social Issues, 57 (3): 389-412.

FIELD, Russell, 2000, "Hockey as a cultural artifact: game eight of the 1972 summit series", em North American Society for Sport History Proceedings. Toronto, LA84 Foundation, 72-74.

FIGUEROA, Arturo, 2003, "Community identity and sports: a social history of soccer in Salinas, California”, Culture Society \& Praxis, 2 (1): 27-32. Disponível em <http://culturesocietypraxis.org/index.php/csp/article/view/23/20>.

GILES, Wenona, 2002, Portuguese Women in Toronto: Gender, Immigration, and Nationalism. Toronto, University of Toronto Press.

GOKALP, Alton, 1988, "Migrants' children in Western Europe: differential socialization and multicultural problems”, em Charles Stahl (org.), International Migration Today, vol. 2: Emerging Issues. Paris, UNESCO/University of Western Australia, 125-137.

GOMES, Frederica, 2008, Selective Expressions of Portugueseness: Notions of Portugueseness among Second Generation Portuguese-Canadian Youth in Toronto. Ryerson University, Toronto, Canada, dissertação de mestrado. Disponível em < http://digitalcommons.ryerson.ca/ cgi/viewcontent.cgi? article $=1090 \&$ context $=$ dissertations $>$.

GRUNEAU, Richard, e David WHITSON, 1994, Hockey Night in Canada: Sport, Identities and Cultural Politics. Toronto, Garamond Press.

GWYN, Richard, 1997, Nationalism without Walls: The Unbearable Lightness of Being Canadian. Toronto, McClelland and Stewart. 
HAY, Roy, 2006, “'Our wicked foreign game': why has association football (soccer) not become the main code of football in Australia?”, Soccer \& Society, 7 (2-3): 165-186.

HIGGS, David, 1990, Portuguese Migration in a Global Perspective. Toronto, The Multicultural History Society of Ontario.

IFEDI, Fidelis, 2005, Sport Participation in Canada, 2005. Otava, Statistics Canada.

JARVIE, Grant, 2006, Sport, Culture and Society: An Introduction. Londres, Routledge.

KING, Russell, e Anastasia CHRISTOU, 2008, Cultural Geographies of Counter-Diasporic Migration: The Second Generation Returns 'Home'. Brighton, Sussex Centre for Migration Research, University of Sussex (Sussex Migration Working Paper, 45).

KLIMT, Andrea, 2002, "Investigating portugueseness: reflections on recent ethnographic approaches”, Diaspora, 11 (2): 277-293.

MAGUIRE, Joseph, 1999, Global Sport: Identities, Societies and Civilizations. Oxford, Blackwell.

METCALfE, Alan, 1987, Canada Learns to Play: The Emergence of Organized Sport, 1807-1914. Toronto, McClelland Stewart.

NOIVO, Edite, 2002, "Towards a cartography of portugueseness: challenging the hegemonic center”, Diaspora, 11 (2): 255-275.

NUNES, Fernando, 1986, Problems and Adjustments of the Portuguese Immigrant Family in Canada. Porto, Secretaria de Estado das Comunidades Portuguesas, Centro de Estudos.

NUNES, João Arriscado, 1995, Boundaries, Margins and Migrants: On Paradigm Shifts, Heterogeneity and Cultural Wars. Coimbra, Centro de Estudos Sociais da Universidade de Coimbra (Oficina do Centro de Estudos Sociais, 55).

OLIVEIRA, Armando, s.d., "Young Portuguese and Portuguese-descendants in Canada: cultural retention and the quest for identity". Disponível em <www.learningmigration. com/files/activity/2/YoungPortCan.doc $>$.

OliveIRA, Armando, e Carlos TeIXeIRA, 2004a, Jovens Portugueses e Luso-Descendentes no Canadá: Trajectórias de Inserção em Espaços Multiculturais. Oeiras, Celta Editora.

— $2004 \mathrm{~b}$, “'Second generation' cultural retention and ethnic identity: young Portuguese and Portuguese-descendants in Canada", Portuguese Studies Review, 11 (2): 1-23.

PACHECO, Debby, 2004, Contested Belongings: Crowding the Portuguese-Speaking Diaspora in Canada. Toronto, Ontario Institute for Studies in Education, University of Toronto, dissertação de mestrado. Disponível em < http://ceris.metropolis.net/Virtual\%20Library/ EResources/Pacheco2004.pdf>.

PANG, Ching Lin, 2000, Negotiating Identity in Contemporary Japan: The Case of Kikokushijo. Londres e Nova Iorque, Kegan Paul International.

PODNIEKS, Andrew, 1996, A Canadian Saturday Night: Hockey and the Culture of a Country. Vancouver, Greystone.

RONALD, Robert, 2007, "Soccer in Canada", Readers Digest, junho. Disponível em <http://www.readersdigest.ca/mag/2007/06/Soccer.php>.

SUÁREZ-OROZCO, Carola, 2000, "Identities under siege: immigration stress and social mirroring among the children of immigrants”, em Antonius Robben e Marcelo Suárez-Orozco (orgs.), Cultures under Siege: Social Violence and Trauma. Nova Iorque, Cambridge University Press, 194-226.

TEIXEIRA, Carlos, e Victor DA ROSA, 2000, The Portuguese in Canada: From the Sea to the City. Toronto, University of Toronto Press. 
TRINDADE, Jani Maria, 2007, Identity and Belonging: Formations of Second Generation Portuguese. Toronto, Ryerson University.

WEVER-RABEHL, Gerba, 2006, "Ethnicity: fluid and permeable, the shifting and changing of ethnic, national and political identity", Suite101.com. Disponível em < http://anthropology.suite101.com/article.cfm/ethnicity_fluid_and_permeable>. 